\title{
The Effect of Topical Application of Mother Milk on Separation of Umbilical Cord for Newborn Babies
}

\author{
Nehal A. Allam ${ }^{1}$, Wafa A. AL Megrin ${ }^{2}$, Amal M.Talat ${ }^{3}$ \\ ${ }^{1}$ Pediatric Nursing, Faculty of Nursing at Ain Shams University, Cairo ,Egypt \\ ${ }^{2}$ Biology, Faculty of Science at Princess Nourah Bint Abdulrahman University, AL Riyadh, Kingdom of Saudia Arabia \\ ${ }^{3}$ Obstetric and Gynecological Nursing, Faculty of Nursing at Ain Shams University, Cairo ,Egypt
}

Email address:

nehall60@yahoo.com (N. A. Allam)

\section{To cite this article:}

Nehal A. Allam, Wafa A. AL Megrin, Amal M.Talat. The Effect of Topical Application of Mother Milk on Separation of Umbilical Cord for Newborn Babies. American Journal of Nursing Science. Vol. 4, No. 5, 2015, pp. 288-296. doi: 10.11648/j.ajns.20150405.16

\begin{abstract}
Global policy regarding optimal umbilical cord care to prevent neonatal illness is an active discussion among researchers and policy makers. The objective of the study is to identify the best available evidence regarding newborn umbilical cord care through, assessing the knowledge of mothers regarding best practice of umbilical cord care and monitoring the effect of both methods of topical mother milk application versus dry method on quickly separation time of umbilical cord stump of newborn babies. The study method is an experimental design. The study result showed that topical application of mother milk on the remaining part of the cord reduces the cord separation time and it can be used as an easy, cheap and noninvasive way for cord care.
\end{abstract}

Keywords: Dry Cord Care, Umbilical Cord, Mother Milk, Separation Time

\section{Introduction}

Umbilical infections are an important cause of neonatal morbidity and mortality in developing countries with incidence rates as high as 55-197 per 1000 live births in community-based studies (Ganatra and Zaidi, 2010). Annually about 3.3 million neonatal deaths occur around the world, Oestergaard et al (2011) reported that, more than $30 \%$ are caused by infections. Some of these infections start as umbilical cord infection. The umbilical cord area supports growth of some harmless or beneficial microorganisms (commensals) whereas others are harmful (e.g., Clostridium tetani). Cord infection may be localized to the umbilical cord (omphalitis) or, after entry into the blood stream, become systemic (e.g., neonatal sepsis) Lawn et al (2005) and Mullany et al (2009). Data on the incidence of omphalitis in low-income countries is generally scarce, the available data estimate the risk to range between 2 and 77 per 1000 live births in hospital settings, with fatality rates of between $1 \%$ and $15 \%$ depending on the definition of omphalitis used. (Mir, et al . 2011).

Moreover the newborn has no protective flora at birth, and normal skin flora begin to be acquired within 24 hours. The first stage of microbial infection is colonization which means the establishment of the pathogen at the appropriate portal of entry. Pathogens usually colonize host tissues that are in contact with the external environment. The umbilicus is colonized by bacteria from environmental sources such as the mother's vagina, her skin flora, and the hands of caregivers so; colonization rates with pathogenic organisms and infections are significantly lower in rooming-in babies than in babies kept in nurseries (Mullany et al 2003) and ( Nourain, et al 2009).

As cord infections should be preventable in most cases( Capurro, 2004). It is important to identify best cord care practices to reduce neonatal mortality and morbidity and offer an alternative to widespread potentially harmful traditional practices. Examples of such practices include use of traditional herbs mixed with cooking oil or water that has been used to wash an adult woman's genitals (num-bati) or application of ash, breast milk, fluid from pumpkin flowers, powder ground from local trees, cow dung, ghee and saliva that may be applied to the cord area and which may be harmful. (Mullany et al. 2007)and (Mrisho et al. 2008). Factors that delay the process of cord stump separation are the application of antiseptics to the stump, infection and 
caesarean section. Delayed cord separation with antiseptics may be due to destruction of the normal flora around the umbilicus (navel) and a subsequent decrease in the number of leucocytes attracted to the cord (Whaly, et al 2003). In the same stream, Zupan et al. (2004) performed a meta-analysis of twenty-one (21) studies involving 8959 participants to assess the effects of topical cord care in preventing cord infection, illness and death. The researchers found that there were no advantages in terms of the use of antibiotics or antiseptics over simply keeping umbilical cords clean and dry The researchers stated that antiseptic use actually prolonged the time for cord separation.

Human milk contains large amounts of IgA antibodies, and these appear to have a preventive effect on skin infections (Kramer et al., 2001). Human milk also appears to have more general antibacterial and antiviral effects. Besides providing excellent immune support, human milk promotes musculoskeletal repair and growth. Human milk is a source of two classes of major growth factors, namely the transforming growth factors alpha and beta (TGF-A and TGF-B) and the insulin-like growth factors 1 and 2 (IGF-1 and IGF-2) ( Ginjala \& Pakkanen, 1998 ). These growth factors promote muscle and cartilage repair and wound healing (Wilson, 1998). TGF-A and TGF-B are involved in normal cell activities such as embryonic development, cell proliferation, and tissue repair. IGF-1 has pronounced anabolic and wound-healing characteristics. It slows catabolism, and it is the only growth factor that can stimulate muscle growth and repair by itself.

As recommended by Mousa, et al (2006), who described that one of the agents that be used for umbilical cord care is topical application of breast milk and distilled water. Applying human milk to the cord stump is one of the cultural cord care practices used in Turkey. According to the WHO, this could be beneficial in view of the antibacterial factors present in breast milk also; it has a lot of immunologic and anti-infective agents. Colostrum contains significantly quantities of complement components that act as natural antimicrobial agents and is also equipped with protective factors that provide specific and nonspecific passive immunity. On the other hand in (2006) Vural and Kisa reported that, Breast milk may accelerate the complicated process of umbilical cord separation through plymorphonoklear leukocytes present at umbilical cord, photolytic enzymes and other present immunologic compounds Previous studies have reported that cord separation time in topical application of human milk and cord dry care groups was shorter compared to topical application of povidone iodine.

Dore et al., (1998) reported that "Evidence supports the use of dry umbilical cord care in the newborn". Vural and Kisa (2006) performed a pilot study that compared the use of povidone iodine (Betadine), human milk, and dry care. They concluded that dry cord care and topical human milk were associated with shorter cord separation times when compared with povidone iodine use. The cord stump normally dries, epithelializes and detaches from the neonate within 15 days after birth. Following delivery, the umbilical cord stump is colonized, usually with bacteria that are non-pathogenic. Until the cord stump detaches and the umbilical area heals, it is recommended to keep the area clean and dry to prevent an infection. In summary, evidence clearly supports the use of dry cord care or natural drying in newborns. The recommended practice leads to shorter cord separation times without an increase in the current infection rate (Broom and Smith, 2012).

As cord infections should be preventable in most cases( Capurro, 2004). It is important to identify best cord care practices to reduce neonatal mortality and morbidity and offer an alternative to widespread potentially harmful traditional practices. Examples of such practices include use of traditional herbs mixed with cooking oil or water that has been used to wash an adult woman's genitals (num-bati) or application of ash, breast milk, fluid from pumpkin flowers, powder ground from local trees, cow dung, ghee and saliva that may be applied to the cord area and which may be harmful. Mullany et al. 2007)and (Mrisho et al. 2008).

WHO (2006) testified that, in developed countries, individual cases of umbilical cord infections continue to occur in aseptic nurseries . According to McConnell et al., (2004) regardless of the cord care practice utilized, educating the healthcare providers and care givers is essential. Teaching should include the normal appearance of the umbilical cord stump, especially if a "drying" agent is not used. Moreover it is important to ensure that parents receive useful consistent skincare information. For example, a parent information leaflet is being compiled which will provide evidence based information to allow parents to make an informed choice about how they care for their baby's skin.

\section{Significance of the Problem}

The best way to treat the umbilical cord after birth is a controversial issue, especially in developing countries which challenged by many local practices and beliefs. Efforts to identify and implement affordable and effective communitybased interventions for umbilical cord care may reduce the large burden of infection related neonatal mortality in developing countries. This is highlighted by requests from pediatric nurses to improve umbilical cord care according to evidence-based best practice. As a result the new change in practice based on the literature by approaching topical application of the mother milk, since it is free and readily available and it will shorten the cord separation time and improved cord care practices. A better accepting of such practices is vital issue for researchers to proposal a new effective behavioral change strategies to reduce cord infections in the millions of babies born each year.

Aim of the Study.

The study aimed to identify the best available evidence regarding newborn umbilical cord care through: assessing the mothers knowledge regarding best practice of umbilical cord care, comparing the effect of both methods on occurrence of 
bacterial colonization among neonates and monitoring the effect of both methods of topical mother milk application versus dry method on quickly separation time of umbilical cord stump among newborn babies.

\section{Subjects and Methods}

\section{Design and Setting}

An experimental design was used to conduct the study. The study conducted at both settings first one was, Obstetric and Gynecological Hospital, postpartum unit, affiliated to Ain Shams University, Cairo, Egypt and second one was Tertiary Hospital in postpartum unit affiliated to Ministry of Health, Al Riyadh, Kingdom of Saudia Arabia.

Sample

Purposive sample size included 400 neonates were recruited from the postpartum units in the both mentioned settings based on simple random sampling technique

Researchers selected the even numbers of beds who met the following inclusion criteria :

Healthy full term neonates from (38-42 weeks gestation); delivered by caesarean section, normal birth weight from(2.500 to 4000) grams, free from congenital anomalies; roomed-in with their mothers and breast fed. Apgar score at first and fifth minute equal 7 and more, and free from any health problems.

Exclusion criteria:

Neonates with health problems or congenital anomalies who requiring immediate transfer to neonatal intensive care unit.

Tools of data collection

Three tools was used and filled by the researchers to collect data:

Content of tools was decided through an extensive review of literatures and researches about cord care.

1- Structured interview Questionnaire for mothers was conducted to collect data related to the mothers and their neonates. This tool included three parts: the first part includes data related to the mother as code of file, mother's age and educational level; the second part includes data related to the neonate as gestational age, gender and birth weight. Third part includes mother culture, beliefs and habits about cord care. Researchers asked questions in a simple Arabic language and recorded the answers in the structure interview tool. Interview consumed about 10 minutes for each mother .

2- Cord swab bacteriological examination tool.

For group A: who underwent topical application of mother milk. First swab taken (immediately after delivery) of the babies and second swab taken (after 3 days) from delivery, then the specimen was labeled with baby of mother name, room number bed number and delivery date. The specimen sent to the bacteriology laboratory. Also the same way was followed for the group B who practiced dry cord care.

3- Follow up Timetable checklist for monitoring signs of cord healing and separation .

This checklist developed by the researchers and filled by them. This tool included two parts: the first was checklist to follow up the compliance of mothers to type of cord care and the second one, to check the presence or not the signs of cord infection as (redness, swelling, secretion of blood or pus, odor or tenderness) until cord detachment occur.

Tools Validity

Tools submitted to a panel of five experts in the field of neonatology, maternity nursing and obstetric medicine to test the content validity. Modification was carried out according to the panel judgment on clarity of sentences and appropriateness of the content.

A pilot Study:

It was conducted on $10 \%$ of the total sample to measure clarity of items practicability of the study tools , and determine the feasibility of the study. Tools was empirically validated by 5 experts for content and construct. They agreed that tools has the ability to measure its objectives. According to the pilot study results, the necessary modifications carried out .All mothers and their neonates participated in the pilot study were excluded from the research sample.

Procedure Technique Plan:

This study was conducted in a period of 19 months from June 2013 up to December 2014 . Agreement to conduct the study was obtained from the Head of the postpartum Units in both settings, also nurses and mothers agreement to participate in the study was obtained.

The plan of study was carried out through the following phases:

1- Assessment phase:

This phase included activities related to reviewing of related literature review. Evidence based practice and current national/international guidelines related to umbilical cord practices reviewed using the CINHL database along with the Cochrane Database of Systematic Reviews. Meeting with nurses that currently working in labor and delivery, postnatal units at both settings, obstetrician, pediatrician, and to debate current umbilical cord care practice.

The Ethical review of the study design was obtained. The researchers allocated one month to collect data about the study literature reviewing and one month to obtain agreement and interview panel in both settings to discuss the study objectives and way of intervention to all nurses staff and to be sure not to apply anything otherwise the study protocol for the selected cases.

2- Implementation and data collection phase:

At the beginning of the study, the researchers presented the best evidence practice about the way of cord care via a 30 minutes lecture, using power point presentation to the nurses in three hospitals shifts at the both settings to gain their understanding and cooperation.

Each mother was interviewed for 10 minutes to determine her perception about cord care best practice . Explanation for the mothers in both groups was done either group( A) about new method of topical application of their mother milk on umbilical cord of their babies or for the mothers in group B about keeping cord clean and dry .This to get their agreement to participate in the study . 
After getting mother consent, the researchers labeled the coat of baby by blue card to ensure from safety of the study sample. Data was collected through the designed tools and instruments and investigated the sample under microscopic in the lab. as the following:

Two groups were constituted 400 neonates, each chosen according to the random assignment into group(A) who received cord care with topical application of mothers breast milk, and group (B) who received with dry cord care. The researchers determined certain days of the week to collect data from both groups. Researchers collected data four days per week ( Friday \& Saturday \& to collect data from group A, ( $8 \mathrm{am}-10 \mathrm{pm})$, Sunday \& Monday to collect data from , (3 $\mathrm{pm}-10 \mathrm{pm}$ ), and same manner for group B.

Group A: After mothers had been fully informed about the research and consented for participation in the research. The researchers ensure safety and prevention of the potential risk by enforced good hand washing by mothers prior to implementation of both methods of cord care. Researchers gave each mother instructions about way of cleaning the umbilical cord stump and the surrounding skin area 3 times per day and as needed during diaper care.

Mothers instructed after washing their hands with water and soap to squeeze foremilk drops (before lactation) on the remaining part of the cord about 4-6 drops and its cut edge and let the milk get completely dry .The application of the care beginning 4 hours after birth to ensure the mother became alert after cesarean section operation. The researchers' asked the mother to apply milk drops 3times per day until cord separation and 2 days after. Nothing was applied to the umbilical cord stump, including topical agent with breast milk and the mothers were delivered cesarean section to ensure follow up of the baby condition for 4 days at the hospital. Emphasize the mothers to keep diaper folded under the umbilical stump area to enhance dryness, healing and prevent contamination for both groups.

Group B : After mothers had been fully informed about the research and consented for participation in the research. The researchers were taught the mothers to leaving the cord clean and dry alone after cutting the umbilical cord and clean it with sterile water, then allowing the cord to complete dryness and separate when it is ready.

Mothers in both groups were recommended not to use any other compound on umbilical cord. If the cord does become soiled with urine or stool, asked the mother to gently wipe it along the entire cord from the umbilical base upward by one cotton, then used another one cotton to clean thoroughly and around the sides of the stump by wet cotton ball and dry the cord with gauze. The Mothers were instructed to follow similar home cord care handling. Cotton and gauze sponges was given to the mothers at the time of discharge.

The researcher developed educational booklet and gave it to the mothers in both groups, it involved information about the method of cord care, and how the mother preserve the baby's diaper folded below the umbilical cord stump to prevent contamination by baby urine and stools and to keep cord stump exposed to air and umbilical cord stump will change from yellowish green to brown to black as it dries out and eventually falls off within 10days or less. The mother informed to keep the umbilical cord stump and surrounding skin clean and dry, way of sponge bath . Warning signs to call the researchers to make referral to the hospital if her baby develops any potential risk factors. Mothers informed that it is normal to notice some oozing of fluid for two days after the stump fell off. These instruction consumed about 10 minutes for each mother.

For both group (A\&B): As soon after delivery the researchers took the first swab from base of umbilical cord stump immediately after admission to postpartum unit to be a base line data, and the second swab was taken on the third day of delivery, to detect early the occurrence of colonization.

If the situation go smooth, the researcher asked the mother to follow same manner after discharge for 7 days more and instructed her to come to hospital soon ,if any infections signs appear(redness, hotness, swelling ,pus, bad odor...etc.) . Home visit was carried out in case of inability of the mothers not able to attend the baby in the promised time at the hospital.

The cord generally falls off in 7 to 10 days.

Bacteriological examination

The swab was taken from the baby by a trained technologist immediately after delivery and direct it to the laboratory for investigation. The technologist monitored the swabs for bacterial growth as the following schedule: first 24 hours after collecting the swabs if any infection detected ,the baby excluded from the study, if there was no bacterial growth, the study carried on and the technologist followed the sample to confirm the result and talked another sample on the $3^{\text {rd }}$ day after delivery to be sure from integrity of the research process.

Follow up time table for signs of cord infection: The researchers follow up the compliance of mothers in both groups regarding instructions of cord care using checklist, to register symptoms signs of cord infection, cord bleeding ,secretion from the cord and the day of cord detachment for 4 day before the mother discharge . Mothers completed these forms at home for 2 days after umbilical cord separation. Then Researcher called mothers daily to get informed on date and hour of cord separation as well as eventual complications after cord separation containing bleeding, mucoid secretions and colonization of granuloma tissue. This to ensure from integrity of the process of cord fall off and to measure and record the duration of cord separation from the date of birth. The researchers encouraged the mothers to feel free to request help if they had any problems or questions. Two days after cord separation, the researchers checked umbilical cord cords of the newborns .

4- Data analysis phase

This phase related to analyses the collected data using computer, SPSS version 20 and finding obtained.

5- Final Report dissemination phase. Conclusions and recommendations obtained from the data and the final report be written at the end of this phase. 


\section{Ethical Consideration}

An official permission was granted from the directors of the hospitals. The researchers introduced themselves to mothers who had neonates and met the inclusion criteria and informed them about the purpose of this research in order to obtain their acceptance to participate in this study. The researchers assured them, that the research posed no risk or hazards on their neonates. All mothers and nurses were knowledgeable that, participation in the study is voluntary and they can withdraw from this study at any time. A written informed consent was obtained from mothers who were keen to participate in the study.

\section{Results}

ble(2) Variale Table (1) illustrate that, the mean age of the mothers in group (A) were $25.9 \pm 5.2$, half $(50 \%)$ of the mothers were educated to the university level , $(40 \%)$ of them educated to diploma level and only (5\%) got master degree. Regarding group (B), the mean age of the mothers were $21.4 \pm 5.4$,it is clear that majority of the mothers got diploma and none of them got master degree. Concerning parity , the majority $(78 \%)$ of the mothers in group (A) had from 2 to 3 children, nevertheless the mothers in group (B), more than two thirds $(65 \%)$ had from 4 to 5 children. Adding that boys constituted more than half $(51 \%)$ in group (A), where girls constituted (53\%)in group (B).

Table 1: Socio-demographic Characteristics of mothers and their neonates among two groups of the study.

\begin{tabular}{|c|c|c|c|c|}
\hline \multirow{2}{*}{$\begin{array}{l}\text { Variables } \\
\text { Mother's Age/years Mean } \pm \text { SD }\end{array}$} & \multicolumn{2}{|c|}{$\begin{array}{l}\text { Group A Topical application of mother milk } \\
\mathbf{N}=\mathbf{2 0 0}\end{array}$} & \multicolumn{2}{|c|}{$\begin{array}{l}\text { Group B I Dry cord care } \\
\text { N=200 pplication }\end{array}$} \\
\hline & $25.9 \pm 5.2$ & & $21.4=$ & \\
\hline Education Level & NO & $\%$ & NO & $\%$ \\
\hline Illiterate & 00 & 00 & 8 & 4 \\
\hline Read \& write & 10 & 5 & 10 & 5 \\
\hline Diploma & 80 & 40 & 150 & 75 \\
\hline University & 100 & 50 & 32 & 16 \\
\hline Highly educated M S & 10 & 5 & - & - \\
\hline \multicolumn{5}{|l|}{ Parity } \\
\hline Primi Para & 30 & 15 & 12 & 6.0 \\
\hline $2-3$ & 156 & 78 & 22 & 11 \\
\hline $3-4$ & 10 & 5 & 24 & 12 \\
\hline $4-5$ & 2 & 1 & 130 & 65 \\
\hline$>5$ & 2 & 1 & 12 & 6 \\
\hline \multicolumn{5}{|l|}{ Gender } \\
\hline Boys & 102 & 51 & 94 & 47 \\
\hline Girls & 98 & 49 & 106 & 53 \\
\hline Birth weight in kilogram Mean \pm SD & $3.250 \pm 450.14$ & & 3.010 & \\
\hline
\end{tabular}

Table 2: Methods of Cord Care as described by Mothers Before The Study Implementation.

\begin{tabular}{|c|c|c|c|c|c|c|c|c|c|c|c|c|}
\hline \multirow{4}{*}{$\begin{array}{l}\text { Method of umbilical } \\
\text { cord care } \\
\text { Warm cloth water }\end{array}$} & \multirow{2}{*}{\multicolumn{6}{|c|}{$\begin{array}{l}\text { Group A Topical application of mother milk } \\
\mathbf{N}=\mathbf{2 0 0} \\
\text { Frequency of usage }\end{array}$}} & \multirow{2}{*}{\multicolumn{6}{|c|}{$\begin{array}{l}\text { Group B I Dry cord care } \\
\mathbf{N}=\mathbf{2 0 0} \text { pplication } \\
\text { Frequency of usage }\end{array}$}} \\
\hline & & & & & & & & & & & & \\
\hline & \multicolumn{2}{|c|}{ Always No (\%) } & \multicolumn{2}{|c|}{ Sometimes + No (\%) } & \multicolumn{2}{|c|}{ Never No (\%) } & \multicolumn{2}{|c|}{ Always No (\%) } & \multicolumn{2}{|c|}{ Sometimes + No (\%) } & \multicolumn{2}{|c|}{ Never No (\%) } \\
\hline & 70 & 35 & 100 & 50 & 30 & 15 & 30 & 15 & 72 & 36 & 98 & 49 \\
\hline Soap and water & 88 & 44 & 112 & 56 & 00 & 00 & 32 & 16 & 62 & 31 & 106 & 00 \\
\hline Butter & 33 & 16.5 & 24 & 22 & 143 & 71.5 & 12 & 6 & 8 & 4 & 180 & 90 \\
\hline Olive oil & 80 & 40 & 120 & 60 & 00 & 00 & 180 & 90 & 20 & 10 & 00 & 00 \\
\hline Alcohol & 177 & 86 & 23 & 11.5 & 00 & 00 & 50 & 25 & 10 & 5 & 140 & 70 \\
\hline Dusting powder & 155 & 77.5 & 45 & 22.5 & 00 & 00 & 36 & 18 & 34 & 17 & 130 & 65 \\
\hline Breast milk & 12 & 6 & 20 & 10 & 168 & 84 & 4 & 2 & 00 & 00 & 196 & 98 \\
\hline Camphor oil & 52 & 26 & 89 & 44.5 & 59 & 29.5 & 150 & 75 & 50 & 25 & 00 & 00 \\
\hline $\begin{array}{l}\text { Cord Bandaging on } \\
\text { abdomen }\end{array}$ & 10 & 5 & 12 & 6 & 178 & 89 & 20 & 10 & 12 & 6 & 168 & 84 \\
\hline Beta dine & 12 & 6 & 17 & 8.5 & 171 & 00 & 28 & 14 & 33 & 16.5 & 139 & 69.5 \\
\hline Ordinary water only & 5 & 2.5 & 9 & 4.5 & 186 & 93 & 44 & 22 & 72 & 36 & 84 & 42 \\
\hline
\end{tabular}

Number are not exclusive

It clear from table (2) that in group (A), most of the mothers reported that they always using alcohol (86\%)and $(77.5 \%)$ using dusting powder in caring of umbilical cord.
About (44.5\%) informed that they sometimes using camphor oil and only $(6 \%)$ identified that breast milk could use as topical application of umbilical cord .On the other hand in group (B), most of the mothers described that they always 
using olive oil (90\%) and (75) using camphor oil in caring of umbilical cord. More than one third (36\%) well-versed that they sometimes using Warm cloth water and ordinary water only and (2\%) identified that breast milk could use as topical application of umbilical cord.

Table 3: Comparison the cord separation time per days among the 2 groups of the study.

\begin{tabular}{llcll}
\hline \multirow{2}{*}{$\begin{array}{l}\text { Cord separation } \\
\text { time per days }\end{array}$} & \multicolumn{2}{l}{$\begin{array}{l}\text { Application of Breast } \\
\text { Milk Group N=200 }\end{array}$} & \multicolumn{2}{l}{$\begin{array}{l}\text { Dry cord care Group } \\
\mathbf{N}=\mathbf{2 0 0}\end{array}$} \\
\cline { 2 - 5 } & No & $\mathbf{\%}$ & N0 & \% \\
\hline Between 4-5 Days & 160 & 80 & 6 & 3 \\
From 5 to 6 & 40 & 20 & 44 & 22 \\
7and more & 00 & 00 & 150 & 75 \\
\hline
\end{tabular}

From table (3) it is clear that umbilical cord separation was earlier among mother breast milk group than dry milk group. By the way the majority $80 \%$ of breast milk group babies had their cord fallen off at the $4^{\text {th }}$ to $5^{\text {th }}$ day of age and only $(20 \%)$ of them had their cord fallen off at the $5^{\text {th }}$ to $6^{\text {th }}$ day of age. On the other hand, only $11(3 \%)$ of the babies in the dry cord care group had their cord fallen off at the $4^{\text {th }}$ to $5^{\text {th }}$ day of age while the majority $75 \%$ of them had their cord fallen off at the $7^{\text {th }}$ day and more

It is evident from table(4) that the majority of neonates in the breast milk and dry cord groups had normal bacterial colonization where $95 \%$ and $94 \%$ of them respectively developed normal Staphylococcus epidermis. Low percentage $5 \%$ to $6 \%$ of neonates in the breast milk and dry cord groups had hotness and mild redness. Pathogenic organism, only $2 \%$ in the breast milk group developed Escherichia coli and Staphylococcus aureus as compared to $2 \%$ and $4 \%$ in dry cord group.

Table 4: Number and Percentage Distribution of Neonates according to Incidence of Bacterial Colonization.

\begin{tabular}{|c|c|c|c|c|}
\hline \multirow{2}{*}{$\begin{array}{l}\text { Variable } \\
\text { Colonization normally }\end{array}$} & \multicolumn{2}{|c|}{$\begin{array}{l}\text { Breast Milk Group } \\
\mathrm{N}=\mathbf{2 0 0}\end{array}$} & \multicolumn{2}{|c|}{$\begin{array}{l}\text { Dry Milk Group } \\
\mathrm{N}=\mathbf{2 0 0}\end{array}$} \\
\hline & NO & $\%$ & $\mathrm{NO}$ & $\%$ \\
\hline $\begin{array}{l}\text { Elevated baby body } \\
\text { temperature }\end{array}$ & 0 & 00 & 0 & 00 \\
\hline Hotness and mild redness & 10 & 5 & 12 & 6 \\
\hline Moderate or severe redness & 0 & 00 & 0 & 00 \\
\hline Severe redness with pus & 0 & 00 & 0 & 00 \\
\hline Foul odor of cord & 0 & 00 & 0 & 00 \\
\hline Exudates from the cord & 0 & 00 & 0 & 00 \\
\hline Abnormal skin color & 0 & 00 & 0 & 00 \\
\hline $\begin{array}{l}\text { Staphylococcus } \\
\text { Epidermises- normal } \\
\text { Pathogenic Organism } \\
\text { founded }\end{array}$ & 190 & 95 & 188 & 94 \\
\hline Escherichia coli & 4 & 2 & 4 & 2 \\
\hline Staphylococcus aureus & 4 & 2 & 8 & 4 \\
\hline $\begin{array}{l}\text { Acimtobacter (gram } \\
\text { negative) }\end{array}$ & 2 & 1 & 0 & 00 \\
\hline
\end{tabular}

Table 5: Comparison the cord separation median time among the 2 groups of the study.

\begin{tabular}{lllcc}
\hline Variable & \multicolumn{2}{l}{$\begin{array}{l}\text { Application of Breast Milk Group } \\
\text { (Mean } \pm \text { SD) }\end{array}$} & \multicolumn{2}{c}{$\begin{array}{l}\text { Dry cord care Group } \\
\text { N=200 (Mean } \pm \text { SD) }\end{array}$} \\
\hline Cord separation time (days) & 4.2 & 20.45 & 7.12 & 10.39 \\
Bleeding continuation after separation (day) & 1.28 & 2.49 & 3.38 & 3.89 \\
Moucouid secretion after separation (day) & 1.88 & 0.64 & 2.18 & 0.79 \\
\hline
\end{tabular}

Table (5) displays that there were statistically significant differences. The data confirm that the mean cord separation time in the breast milk group was significantly shorter $(p<0.001)$ than in the dry cord care group . The mean cord separation time was $4.2 \pm 20.45$ among mother breast milk group and $7.12 \pm 10.39$ in dry cord care group respectively. On other hand, the bleeding continuation after separation (day) was significantly shorter $(\mathrm{p}<0.001)$ among breast milk group than the dry cord care group. There was no significant difference concerning moucouid secretion after separation in both groups. There were no stated problems at the cord site among both groups.

\section{Discussion}

There is a growing importance on good care of the umbilical cord after birth. However, studies of cord care have focused more often on interventions such as cord clamping time and the use of topical antimicrobials on the stump, and much less attention has been given to practices that are "natural" or cultural.

The researchers found very few literature with the current topic of research. Both Egypt and Kingdom of Saudia Arabia quiet sorrow from high rate of neonate mortality and morbidity ,they could be benefited from comparing the mother breast milk application with no application (Dry method). Mothers in the maternity wards were found apprehensive to institute the mode of pharmacological treatment to the newborn.

The findings of present study have been discussed as per the objectives of the study.

A finding of the study displays that the intervention of mother breast milk application was significantly effective for early separation of the cord as shown in table (3) where the majority ( $80 \%$ ) of breast milk group babies had their cord fallen off at the $4^{\text {th }}$ to $5^{\text {th }}$ day of age as compared by the majority $75 \%$ of dry cord had their cord fallen off at the $7^{\text {th }}$ day and more. Moreover when compared together it was statistically found that there is highly significant difference among the mother breast milk application group and in dry method group in relation to, time of cord stump separation and occurrence of bacterial colonization. These in congruent with, Yonis, (2010) who reported that, umbilical cord stump separation time in human milk group was shorter than in the alcohol group $(4+1 \& 8+2$ days respectively) $(\mathrm{P}<0.001)$.

In this view, the study presented that, the duration of the umbilical cord stump separation time in breast milk group is 
shorter than in the dry cord group by about two days. In spit the umbilical cords were detached in both groups within the normal period between (5-15 days following the birth) as documented in literatures.

As clarified in (table 5), there were statistically significant differences. The researchers found that the mean cord separation time among the mother breast milk group was significantly shorter $(\mathrm{p}<0.001)$ than in the dry cord care group. The mean cord separation time and standard deviation was $4.2 \pm 20.45$ in breast milk group as compared to $7.12 \pm 10.39$ in dry cord care group. On other hand, the bleeding continuation after separation (day) was significantly shorter $(\mathrm{p}<0.001)$ among mother breast milk group than the dry cord care group. There was no significant difference concerning moucouid secretion after separation in both groups. There were no stated problems at the cord site among the both groups. This result is matched with Golshan and Hossein (2013), they specified that the mean of umbilical separation time had significant differences among the three groups $(\mathrm{p}<0.0001)$. The lowest and the highest separation times belonged to human milk and ethanol groups respectively. Among the neonates, the lowest and the highest umbilicus separation times were 3 and 15 days. In post hoc analysis, umbilical separation time in human milk group had significant differences with ethanol $(p<0.0001)$ and drying groups $(\mathrm{p}<0.003)$. On the same line with Dhanawade $(2014)$ who recommended that the totals mean score of breast milk application group after intervention was 5.22 and in control group. (mean 9.36. The research hypotheses (H1) were accepted as breast milk application is highly effective in the early separation of cord stump. Moreover Vural and Kisa (2006) concluded that dry cord care and topical human milk were associated with shorter cord separation times when compared with povidone iodine use.

Furthermore, the present study showed that there was statistically significant difference between mother breast milk topical group and dry cord care where, the bleeding continuation after cord separation (day) was significantly shorter $(p<0.001)$ among breast milk group than the dry cord care group. There was no significant difference concerning moucouid secretion after separation in both groups. There were no stated problems at the cord site among the both groups. The findings of the present study is supported by one of the study which was done by A whonn (2007)who sounds that the normal healing process producing a "mucky appearance. This isolated presentation running head, umbilical cord care of a "mucky" cord has not been associated with infection. Health care providers and parents need to understand the difference between the normal healing process and actual signs of infection. The researchers observed that during the normal separation of umbilical cord process of neonates, small amounts of cloudy mucoid material may collect at that junction, it seem misinterpreted as pus. Moreover, as the cord is drying and separating from the stump, the cord may appear moist, sticky or smelly.

As displayed in table (4) the majority of neonates in the breast milk and dry cord groups had normal bacterial colonization where $95 \%$ and $94 \%$ of them respectively developed normal Staphylococcus epidermis. Concerning Pathogenic organism, the most common cultured organisms illustrated that only $2 \%$ in the breast milk group developed Escherichia coli and Staphylococcus aureus in the umbilical stump as compared to $2 \%$ and $4 \%$ in dry cord group. In the same field Amirfarhani et al (2008) who compared bacterial colonization in umbilical cord in topical application of breast milk and dry cord care. They found that the most common organisms were Staphylococcus aureus, E. coli and Klebsiella and there were statically significant differences between the two groups in colonization rate. They showed that in topical application breast milk group, Staphylococcus epidermidis was more than in dry cord care group and in this, S. aureus, E. coli and Klebsiella pneumoniae was more than in topical application breast milk group $(\mathrm{P}<0.05)$ but this in disagreement with Farahani et al (2008) who reported that there was statistically significance difference between breast milk group and dry cord care group on occurrence of bacterial colonization. High percentage of pathogenic organisms was found in the dry cord care group, statistically significance difference between groups. In the present study, it could be due to the difference in the weather and racial between the samples.

Currently and throughout history, many different substances have been used on the umbilical cord stump to accelerate the drying process and reduce the chance of infection .In the present study, various other modalities mentioned by the mothers in the both groups (table2). Where ,most of the mothers in group (A) reported that they always using alcohol (86\%)and (77.5\%) using dusting powder in caring of umbilical cord.About $(44.5 \%)$ informed that they sometimes using camphor oil and only $(6 \%)$ recognized that breast milk could use as topical application of umbilical cord .On the other hand in group (B), most of the mothers described that they always using olive oil (90\%) and (75) using camphor oil in caring of umbilical cord. More than one third $(36 \%)$ well-versed that they sometimes using Warm cloth water and ordinary water only and (2\%) identified that breast milk could use as topical application of umbilical cord. These results was matched with some researches of (Evens et al., 2004; London et al., 2007; McKinney et al., 2009; Suliman, 2007; Vural \& Kisa, 2006; Zupan et al., 2004). They reported that Some of the methods that have been used on umbilical cord stumps include; plant extracts, coins, olive oil, coconut oil, colostrum, triple dye, povidone- iodine (Betadine), various antibiotics, sterile water, alcohol (70\% isopropyl alcohol), and no treatment at all (Awhonn, 2007).

Concerning maternal satisfaction with the new protocol. All of mothers in the group(A) were surprising from the results of the early level of separation of umbilical cord after topical application of breast milk. The majority of them reported they were happy by the results and it is the first time to follow this way of care. On the other hand all of mothers in the group(B) were surprising from the results of separation of umbilical cord after application dry cord care. The 
majority reported they are amazing by the results and the cord dry off without application of traditional substance.

In the present study, none of the factors, such as age ,level of education or maternal literacy and parity that were associated statistically with differences in cord-separation time or represents an increase of any practical significance.

Umbilical cord care practices for newborns vary between health care settings which can lead to misunderstanding for both parents and nurses. It seems that the current standard of umbilical cord care may be based on historic practices and traditions rather than on scientific investigation and justification. Methods currently used nationwide include; various other modalities as daily cleaning of the umbilical cord with alcohol (70\% isopropyl alcohol), triple dye, sterile water and, dry cord care. Dry cord care will lead to shorter cord separation times and be more cost effective for the hospital. The findings of this study regarding breast milk application to the umbilical cord stump can make the health care workers, specially nurses and doctors aware of it. So that it may be used by all settings for the profit of neonates.

Hoping the findings of the present study leads to avoid the gap between research studies and clinical practice and to deliver practical evidence to inform policy on the implementation of sustainable interventions in neonatal units to decrease neonatal mortality.

\section{Conclusion and Recommendation}

It is important to determine the best practice for umbilical cord care in order to minimize cord infections in the millions of babies born each year. Mothers should be fully up-to-date and understand the aims of umbilical cord care. This should be supported by provision of evidence-based information offered to them. Therefore, it is recommended that topical application of mother milk on the remaining part of the cord reduces the cord separation time as compared with dry cord care and it can be used as an easy, cheap and noninvasive way for cord care. Further research is proposed to confirm the results and to evaluate the effect of the implementation of these methods on improvement of the umbilical cord care.

\section{Acknowledgment}

The researchers is gratefully acknowledged for all mothers contributions towards the completion of the study. Further, acknowledgement is accorded to Doctors Ahmed Atef and Norah Al Sadhan for their kind help and cooperation throughout the study.

\section{References}

[1] Amirfarhani L, Tafazol M, Mohammadzade A. (2008).Assess of topical application of human milk in cord separation time in healthy neonate.J Sabzevar Med Sci Uni;14(3):165-71[I n Persian].

[2] Awhonn. (2007). Association of Women's Health, Obstetric and Neonatal Nurses. Evidence- based clinical practice guideline: Cord care. Neonatal Skin Care: Evidence - Based Clinical Practice Guideline (2 nd ed). Washington D. C.

[3] Broom, MA., and Smith, SL. (2012) Late Presentation of Neonatal Omphalitis Following Dry Cord, Care. Clinical Pediatrics, 52(7), 675-677.

[4] Capurro H. (2004).Topical umbilical cord care at birth: RHL commentary. The WHO Reproductive Health Library.

[5] Dhanawade RA .(2014). Innovations in Pharmaceuticals and Pharmacotherapy. IPP, Vol 2(3), 386394 .www.innpharmacotherapy.com .eISSN: 2321.

[6] Dore, S, Buchan, D, Coulas, S, Hamber, L, Stewart, M et al. (1998) .Alcohol versus natural drying for newborn cord care. J Obstet Gynecol Neonatal Nurs 27 (6), 621-627.

[7] Ganatra HA, Zaidi AKM . (2010).Neonatal infections in the developing world. Semin Perinatol; 34: 416-25.

[8] Ginjala V\& Pakkanen R. ( 1998 ). Determination of transforming growth factor- beta1 and2 insulin-like growth factor in bovine colostrum samples.J immunoassay, 19:195207.

[9] Golshan, Hossein N. (2013)Impact of ethanol, dry care and human milk on the time for umbilical cord separation .JPMA 63: 1117; . Vol. 63, No. 9.

[10] Evens, K., George, J., Angst, D., \& Schweig, L. (2004). Does umbilical cord care in preterm infants influence cord bacterial colonization or detachment? Journal of Perinatology(24), 100104.

[11] Farahani, L.,Mohammadzadeh,A., Tafazzoli,M.,Esmaeli,H.,\& Ghazvini,K. (2008). Effect of topical application of breast milk and dry cord care on bacterial colonization and umbilical cord separation time in neonates. Journal of Chinese Clinical Medicine, 3(6): 327-332.

[12] Kramer M S, Chalmers B, Hodnett ED, Sevkovskaya Z,Dzikovich I,Shapiro S,etal. (2001 ). Promotion of breast feeding intervention trail(PROBIT).A randomized trial in Republic of Belarus .JAMA.285:413-20.

[13] Lawn JE, Cousens S, Zupan J.(2005).Lancet Neonatal Survival Steering Team. 4 million neonatal deaths: when? Where? Why? Lancet.;365:891-900.

[14] London, M.L., Ladewig, P.W., Ball, J.W., \& Bindler, R.C. (2007). Maternal \& Child Nursing Care(2 nd ed). Pearson: Upper Saddle River.

[15] McConnell, T.P., Lee, C.W., Couillard, M., \& Sherrill, W.W. (2004). Trends in umbilical cord care: Scientific evidence for practice. Newborn and Infant Nursing Reviews(4), 211-222.

[16] McKinney, E.S., James, S.R., Murray, S.S., \& Ashwill, J.W. (2009). Maternal- Child Nursing (3 rd ed). Elsevier: St. Louis. RUNNING HEAD: Umbilical Cord Care 20.

[17] Mir F, Tikmani SS, Shakoor S, et al. (2011).Incidence and etiology of omphalitis in Pakistan: a community-based cohort study. J Infect Dev Ctries.;5: 828-833.

[18] Mousa, A., Yadollah,Z., karimollah,H, Ghasem, J., Hamid, T. (2006). The effect of topical application of human milk, ethylalcohol $96 \%$, and silver sulfadiazine on umbilical cord separation time in newborn infant. Archives of Iranian Medicine, Volume 9, Number 1, 33 - 39. 
[19] Mrisho M, Schellenberg JA, Mushi AK, et al.(2008).Understanding home-based neonatal care practice in rural southern Tanzania. Trans R Soc Trop Med Hyg.;102:669678.

[20] Mullany LC, Darmstadt GL, Tielsch JM. (2003).Role of antimicrobial applications to the umbilical cord in neonates to prevent bacterial colonization and infection: a review of the evidence. Pediatr Infect Dis];22(1):996-1002.

[21] Mullany, L.C., Daymstadt, G.L., Katz, J., Khatry, S.K., Lecclerq, S.C., and Adhikari, R.K.( 2007). Risk factors of umbilical cord infection among newborn of southern Nepal. Epidimology Amirican Journal;165:203-11.

[22] Mullany LC, Darmstadt GL, Katz J, et al. (2009).Risk of mortality subsequent to umbilical cord infection among newborns of southern Nepal: cord infection and mortality. Pediatr Infect Dis J.;28:17-20.

[23] Nourain, M., Allaii, F., and Heidari, A. (2009). Comparison of the effect of alcohol $70 \%$ versus dry cord care on cord bacterial colonization and cord separation time among newborns. Pak Medical Science Journal; 25(1):103-107.

[24] Oestergaard MZ, Inoue M, Yoshida S, et al.( 2011).United Nations Inter-Agency Group for Child Mortality Estimation and the Child Health Epidemiology Reference Group. Neonatal mortality levels for 193 countries in 2009 with trends since 1990: a systematic analysis of progress, projections, and priorities. PLoS Med.;8:e1001080.

[25] Suliman, A. (2007). Triple dye plus alcohol versus triple dye alone for newborn umbilical cord care. Pennsylvania State Milton S. Hershey Medical Center.ClinicalTrials. gov identifier: NCT00127699.
[26] Vural G,Kiza S.Umbilical cord care.(2006).a pilot study comparing topical human milk,povidone-iodine, and dry care.Journal of Obstetrics,Gynecologic, and Neonatal Nursing, ,35(1):123-128.

[27] Whaly, L.F., and Wong, D. (2003). Nursing care of infants and children. 7th.ed. Mosby- Year Book, New York.

[28] World Health Organization (WHO) (2006) Postpartum care of mother and newborn, Care of the umblical cord., Family and Reproductive Health, Division, of Child Health and Development. Evidence for the ten steps to successful breastfeeding. 1998 [cited May 22, 2006]; Available at: www.who.int/child-adolescenthealth/New_Publications/NUTRITION/WHO_CHD_98.9.pdf.

[29] World Health Organization. WHO Recommendations on Postnatal Care of the Mother and Newborn. 2013. http://apps.who.int/iris/bitstream/10665/97603/1/9789241506 649 eng.pdf.

[30] Yonis, E.S. (2010). The effect of topical application of human milk comparable with $70 \%$ ethyl Alcohol on umbilical cord separation time in newborn infant at Minia University Hospital. Unpublished thesis.

[31] Zupan J, Garner P. Topical umbilical cord care at birth(Cochrane Review). In: The Cochrane Library, Issue 3.Chichester, UK: John Wiley and Sons: Update Software, 2004.

[32] Zupan, J., Garner, P., \& Omari, A. (2009). Topical umbilical cord care at birth. The Cochrane Collaboration, .Cochrane Database Systemic Review, (3): CD 001057. 